\title{
Impact of simulated patients on physiotherapy students' skill performance in cardiorespiratory practice classes: a pilot study.
}

WALKER, C.A. and ROBERTS, F.E.

2020 
Impact of simulated patients on physiotherapy student skill performance in cardiorespiratory: A Pilot Study

Authors - Walker CA ${ }^{1}$, Roberts FE ${ }^{1}$, Hammerton $\mathbf{J}^{2}$

Affiliations: ${ }^{1}$ School of Health Sciences, Robert Gordon University, Scotland, UK.

${ }^{2}$ Faculty of Health and Wellbeing, Sheffield Hallam University, Sheffield, England, UK

Qualifications - Walker CA MSc Advancing Physiotherapy Practice, BSc (Hons) Physiotherapy

Roberts FE MSc Physiotherapy (Respiratory), BSc Physiotherapy, PGCert LTHE

Hammerton J PhD, Grad. Dip. Phys

Contact details - Craig Walker c.a.walker3@rgu.ac.uk 


\section{$1 \quad \underline{\text { Abstract }}$}

2 Background - To date there is no evidence that high fidelity simulation (HFS)

3 improves skill development within the university setting in physiotherapy students.

4 With pressures to reduce costs and maintain/improve quality of the learning

5 experience and pressures on clinical placement, it is essential to investigate methods

6 that can improve student skill performance before they undertake clinical practice.

7 Objective - To investigate 1) The impact of using Simulated Patients (SPs) in a

8 practical class on physiotherapy student skill acquisition; 2) student reflections

9 regarding the intervention.

10 Design - Pilot study using a single centre (University Clinical Skills Centre)

11 randomised controlled trial.

12 Methods- Twenty eight undergraduate physiotherapy students matched using

13 previous practical examination grades undertook a two hour practical class where core

14 cardiorespiratory skills were practiced. Pre session resources were identical. Control

15 group practiced on peers, intervention group practiced on SPs. Student's skill

16 performance was assessed two weeks after the class using the Mini Clinical

17 Evaluation Exercise (MiniCEX) including qualitative data from student reflections.

18 Results: Twenty eight students undertook the practical class and subsequent

19 MiniCEX assessment. A statistically significant difference was found for all aspects

20 of the MiniCEX except medical interview $(\mathrm{p}=0.072)$ and physical interview

21 ( $\mathrm{p}=0.688)$. A large effect size was found for all areas except physical interview

$22(0.154)$ and medical interview (0.378). Student reflections focused on three key

23 themes: behaviour and attitudes, teaching the skill, and feedback. 
25 Limitations: As a pilot study, data was collected from a small sample based in one

26 university. This limits conclusions relating to statistical significance and

27 generalizability. Additionally the MiniCex is not validated to assess psychomotor

28 skill performance questioning the validity of conclusions.

29 Conclusions: Findings of this study suggest SP interactions may improve student

30 skill performance, however, further research using a larger sample size and using an

31 outcome validated for this population is required.

32 Key Words - Simulation, Standardised Patients, Physiotherapy, Undergraduate

33 Education, skill development

34 Word Count - 3166

35

36

37

38

39

40

41

42

43

44

45

46

47

48

49

50

51

52

53

54

55

56 
59 Periods of supervised clinical practice are a core element of pre-registration

60 physiotherapy education programmes. ${ }^{1}$ During these clinical periods, students are

61 responsible for assessing and treating real patients with real conditions/problems.

62 Consequently, assessment and treatment techniques will have real and visible effects.

63 To ensure students can undertake this clinical practice safely and effectively, it is

64 important they achieve deep learning within their university learning. ${ }^{2}$ It is imperative

65 that students understand what they are doing, the underpinning rationale, and potential

66 consequences. It is also important to have sufficient skill performance to be able to

67 apply techniques safely and effectively.

68

69 The basic skills students' use during clinical periods are taught in the university

70 setting in the first instance, through a combination of theoretical and practical

71 learning. Traditionally, practical learning is undertaken with students practicing on

72 each other, defined as peer practice. ${ }^{1}$ However, to achieve the deep and meaningful

73 learning required to be able to transfer the learning to real clinical practice, students

74 need to be exposed to situations that will challenge their knowledge and experience,

75 as this will require them to reframe their knowledge, in essence, achieving deep

76 learning. ${ }^{3}$

78 For effective learning to occur in clinical practice, it has been proposed that students

79 must achieve basic levels of the hierarchy of competence: feeling safe and secure,

80 self-efficacy, and knowledge and experience of what to expect in the clinical

81 environment. ${ }^{4}$ Peer practice in university can allow students to feel safe and secure 
82 and to gain a level of self-efficacy, however, the experience of what to expect in a real

83 clinical situation is not addressed. Students are also more comfortable with each

84 other; they know what is expected of them with each technique and consequently

85 react appropriately. ${ }^{5}$

86

87 Shulman's Table of Learning suggests that engagement and motivation are required

88 for deep learning; only once this is achieved can students' move forward to the

89 psychomotor domain, the effective performance of skills. ${ }^{6}$ This is supported by Sabus

$90 \&$ Macauley who discuss the circumplex model of affect; students will learn more

91 effectively when there is an element of nervousness/tension/ excitement, essentially

92 when students are alert and engaged. ${ }^{7}$ When working with peers it is challenging to

93 maintain the alertness required for the focussed and repetitive practice necessary to

94 achieve skill competence, there is no pressure to modify and correct techniques if

95 peers do things correctly. ${ }^{7}$

Internationally reported pressures relating to challenges to placement provision and sufficient student supervision during clinical practice periods mean it is critical that student skills are as strong as possible before they are exposed to the real clinical

101 environment. ${ }^{8,9}$ This will give them the confidence to learn effectively and minimise 102 pressures on already stretched clinicians while ensuring patient safety. ${ }^{10}$

104 Since Korpi et al indicate that student's expertise is built in real work situations, ${ }^{11}$

105 alternative learning methods such as high fidelity simulation (HFS) 'Simulation 106 experiences that are extremely realistic and provide a high level of interactivity and 
realism for the learner; Can apply to any mode or method of simulation; for example: human, manikin, task trainer, or virtual reality' ${ }^{12 p 15}$ may be beneficial.

110 Simulation Based Learning (SBL) provides a continuum of complexity and realism

111 and can provide a range of clinical situations from the commonplace to the less

112 frequent but more challenging experiences. This enables students to evaluate the

113 effect of, and modify, interventions as a consequence of 'patient' responses, akin to

114 real situations. Simulated learning already has a strong place in medical and nursing

115 education. ${ }^{13}$ In addition Blackstock et $\mathrm{al}^{14}$ and Watson et $\mathrm{a}^{15}$ both demonstrated that

116 HFS could replace clinical practice without detriment to student performance in

117 cardiorespiratory and musculoskeletal physiotherapy areas.

119 However, a wider review of physiotherapy literature shows a small and generally poor 120 quality evidence base relating to HFS with a strong focus on investigating its impact

121 in cardiorespiratory teaching. Findings to date highlight positive student perceptions ${ }^{16}$,

$12217,18,19$ and possible benefits to application of knowledge. ${ }^{20,21}$ Only one pilot study

123 appears to have assessed whether HFS improves skill performance in physiotherapy

124 students. $^{22}$ Phillips et al compared a group of 37 students who experienced HFS using

125 simulated patients (SP) to practice their patient assessment skills and ability to

126 mobilise a patient safely to a control group (traditional peer practice) of 36 students. ${ }^{22}$

127 They found poorer skill performance in the HFS group than the control group.

128 However, students had no prior experience of HFS, which may have increased stress

129 levels and inhibited their learning. ${ }^{7,23}$ 
131 To date there is no evidence that HFS improves skill development in physiotherapy

132 students compared to traditional teaching and learning approaches. Only one pilot

133 study suggests it provides no benefit. As with the health services, universities are

134 experiencing pressures to reduce costs, but maintain, if not enhance, the quality of the

135 learning experience. ${ }^{24}$ As a result, with simulation being a costly method of teaching,

136 evidence to support this method of learning is required if it is to continue to be

137 utilised. ${ }^{22}$

138

$139 \underline{\text { Aim }}$

140

141 The aim of this exploratory study therefore were to 1) investigate the impact of

142 incorporating SPs into a physiotherapy practical class on student performance of core

143 cardiorespiratory skills, and 2) gather initial student views on this learning method

144 through their reflections.

$146 \underline{\text { Method }}$

147

$\underline{\text { Study Design }}$

An exploratory pilot study using a single blind randomised controlled method with an

151 embedded qualitative component was undertaken. ${ }^{25}$ This enabled quantitative

152 measurement of skill performance through use of the mini clinical evaluation exercise

153 (MiniCEX), with qualitative data gathered from student reflections. ${ }^{26,27}$

154

155 A current lack of evidence in this area indicated that an initial exploratory pilot study

156 was appropriate to establish if the intervention appears to have an effect and also to 
investigate student views on the learning approach compared to the traditional low

158 fidelity learning experiences. This would then indicate the value of undertaking

159 further study in this area and, if appropriate, provide effect sizes for a larger

160 randomised controlled trial.

162 At the study institution, grades are calculated (A-F) and consequently a matched 163 pair's design allowed allocation of students with comparable ability across both

164 groups and consequently more accurate comparison of results between the SPs (HFS

165 group) and a control group, who received traditional peer practice [low fidelity

166 simulation (LFS) $].^{28}$ The study was approved by the School of Health Sciences

167 Research Review group (ref no:SHS/16/02); gatekeeper approval was gained from the course leader.

\section{$\underline{\text { Participants and Setting }}$}

172 A convenience sample of students from year two of a four year BSc (Honours)

173 physiotherapy programme at one Scottish University were invited to participate in the

174 study. The primary researcher explained the study to all students in the year during a

175 class at the start of their Acute Care module which commenced in semester two. This

176 was followed-up with an e-mail invitation and participant information sheet. Although

177 students had received an introduction to cardiorespiratory skills in year one where

178 they had briefly practiced the skills on each other, previous experience from teaching

179 the Acute Care module showed that retention of these skills was negligible. This

180 module is the main opportunity students have to develop these core skills before using

181 them in practice. Students were advised they would be randomly allocated to a peer 
practice group (LFS) or one that would practice the same skills on SPs (HFS). They were also advised participation was voluntary, non-participation would not disadvantage them in any way, and that they could withdraw from the project at any

185 time with no impact on their module assessment grade. To reinforce this, the module

186 leader was not involved in data collection for the study. Those who wished to

187 participate were asked to reply to the invitation email and to provide written informed consent.

The year two students had undertaken three clinical placements, focused on care of

191 the elderly, outpatient musculoskeletal, community, orthopaedic or neurology areas

192 before this module. They had also experienced working with SPs during HFS to 193 practice assessment skills, including subject history taking and objective testing, in 194 these areas. During these activities the SPs work to a case scenario and provided 195 students with feedback on core professional areas such as communication and 196 handling skills, empathy and caring.

198 All 31 students in the year two class agreed to participate but only 28 attended the 199 practical class and could be included. Blocked randomisation was undertaken which 200 enabled a matched pair design. Students were matched into pairs, with the blocking 201 variable being practical exam results from the preceding module (Grade A-F). They 202 were then randomly assigned to either the HFS $(n=14)$ or LFS group $(n=14)$, using the 203 sealed envelope method of randomisation by a member of the physiotherapy team 204 independent of the study and module. 
208 Acute care is taught with a combination of directed study, followed by

209 tutorials/workshops where students actively apply theory to clinical situations. The

210 aim is to promote deep learning. Students also have access to videos detailing the

211 teaching and application of core respiratory techniques, including Active Cycle of

212 Breathing Technique (ACBT). Practical classes are traditionally undertaken in the

213 simulated ward environment, where students practice skills on each other and receive

214 feedback from staff and peers. The ward environment encompasses two six bedded

215 hospital bays which enabled both groups to be taught simultaneously. Each bed space

216 has a bed, patient locker and chair and can be separated from the next bed space by

217 curtains and replicates the environment students will work in during clinical

218 placements. The learning outcomes for both groups were the same:

219 - To practice teaching the three components of ACBT (breathing control,

220 thoracic expansion exercises and forced expiratory technique).

221 - To develop skills in modifying ACBT for patients with breathlessness, sputum

222 retention and loss of volume.

223

224 The LFS group practiced the skills on their peers, working in threes; one patient, one

225 therapist and one student providing feedback. They were advised to remember to put

226 themselves in the position of a patient and to respond appropriately to instructions, for

227 example if instructions were not clear they were to do what they thought was being

228 asked rather than what they knew they should do. The HFS group undertook their

229 practical class applying and modifying the same treatment techniques on SPs instead

230 of peers. Other than the models for practicing the technique both groups received the

231 same experience. Eight SPs were used for the intervention group ensuring students 
generally worked in pairs, one teaching the 'patient', while the other took notes and provided feedback to their peer. These students also received feedback from the class tutor in the same way as the control group, and feedback from the SPs.

The role of SPs was undertaken by members of the volunteer patient bank within the university. They are members of the local community who volunteer to take on the role of SPs to facilitate student learning. They have diverse backgrounds and on joining the patient bank receive training on the requirements of the 'patients' and

240 providing constructive feedback. Prior to each class the SPs are briefed by the class

241 tutor about what is required of them. Where patient scenarios are used these are sent

242 to the SPs at least two weeks in advance of the session. Each volunteer receives a $£ 20$

243 gift voucher for each period of up to four hours that they are working with students.

245 For the purposes of this class the SPs were not performing to a specific patient

246 scenario. They were briefed prior to the class about the purpose of the research and

247 that students would be teaching them various breathing techniques. As the SPs had

248 not been involved in these practical classes the techniques were novel to them and

249 they were advised to be themselves. If students did not explain the techniques clearly

250 they were to do what they thought the instructions meant. If they felt the need to ask a

251 question then to do so in the same way a patient would. Students would have to focus

252 on their explanations and problem solve ways to help the SPs achieve the correct

253 techniques. No attempts were made to standardize how the SPs responded so that

254 students experienced more of the reality that patients vary in how they respond.

255 During the practical class students worked with different SPs to enable them to have 256 to modify their explanations depending on the different SPs responses. 
258 In the two hour class, both groups practiced the three components of ACBT, in

259 addition to modifying ACBT for breathlessness, sputum retention and lung volume

260 loss. The classes involved low psychological fidelity simulation and consequently

261 'patients' were not attached to equipment or wearing costumes. This is typical for our

262 practical classes. Those in the HFS group received feedback from a peer, from the SP

263 through their responses (and explicit feedback about the clarity of their explanations,

264 handling and approach to the 'patient') and from the class tutor. This was provided on

265 the basic skills before the students and SPs were advised the patient had 1)

266 breathlessness, 2) sputum retention and 3) volume loss. Students then had to explain

267 the 'problem' to the SP and modify the techniques as appropriate.

268

269 The classes for the HFS and LFS groups ran concurrently with a different tutor

270 facilitating each practical class to prevent contamination. This ensured students did

271 not get an opportunity to talk to each other about their in class experience until it was

272 completed. The tutor for the LFS group had one year of teaching experience in a

273 university setting and 4 years of clinical experience: the tutor facilitating the HFS

274 group had 14 years of teaching experience in a university setting and 12 years of

275 clinical experience. Prior to the class the tutors were briefed on the session learning

276 outcomes and given a clear teaching plan (supplementary data) which detailed

277 facilitation activities.

278

279

$\underline{\text { Outcomes }}$ 
281 No specific validated cardiorespiratory physiotherapy outcome measures were

282 identified. ${ }^{29}$ Consequently, the MiniCEX was utilised. ${ }^{26,27}$ It assesses communication,

283 professionalism, counselling, attitudes and behaviours and has been shown to be valid

284 and reliable for the assessment of clinical skills and competence in medical students. ${ }^{30}$

285 The student assesses and treats a patient, whilst the clinician rates the student on a

286 Likert scale and provides formative feedback. The reflective component of the

287 MiniCEX provided the opportunity for students to provide information on their self-

288 rated competence, confidence and views of their learning experience (Table 1).

290 The practical class for ACBT was undertaken in the second week of the six-week

291 module. Data collection was undertaken during the third week only by the primary

292 researcher who was blind to group allocation. Formative feedback on their

293 performance was given immediately on completion of the MiniCEX. Students' then

294 completed the self-reflection component of the MiniCex before returning it to the

295 primary researcher and leaving the room.

$\underline{\text { Data Analysis }}$

The MiniCEX rates students on a Likert scale (well below expectation for stage of training to well above expectation for stage of training). The six points of the Likert

301 scale were allocated a numerical value $(0=$ well below expectation, $1=$ below

302 expectation, $2=$ borderline, $3=$ meets expectations, $4=$ above expectations, $5=$ well

303 above expectations). This ordinal data enabled the non-parametric Wilcoxon Matched

304 Pairs Signed rank test to be used to compare the matched pairs' performance (SPSS

305 Version 25, IBM Corp, Armank, New York, USA). Due to the small sample exact test

306 results are reported. Statistical significance was set at $\mathrm{P} \leq 0.05$. Effect size for the 
307 Wilcoxon Signed Rank tests were calculated. ${ }^{31}$ Associations between the HFS and

308 LFS group were investigated using Chi Squared.

309

310 Qualitative data from student reflections was analysed by the two primary researchers

311 using a modified thematic framework analysis based on that proposed by Spencer,

312 Ritchie and O'Connor. ${ }^{32}$ The researchers, both cardiorespiratory specialists, each have

313 more than 10 years of clinical experience and more than 7 years' experience of

314 working in a university teaching students. Additionally both have an interest in the

315 use of HFS as a learning method. To prevent bias, reviewers independently identified

316 themes and then met to compare and agree those that were appropriate. Data for each

317 group was kept separate. Due to the small amount of qualitative data the descriptive

318 but not explanatory stage of framework analysis was applied. ${ }^{32}$

\section{$\underline{\text { Results }}$}

322 Data was collected for 28 students. Demographic data for the LFS and HFS groups is

323 provided in Table 2. Table 3 shows the results achieved by each matched pair. The

324 Wilcoxon Signed Rank Test suggest statistically significantly higher medians for the

325 HFS group in all aspects except medical interviewing skills $(\mathrm{p}=0.72)$ and physical

326 interviewing skills ( $\mathrm{p}=0.688$ ) (Table 3 ). The effect sizes for Wilcoxon signed rank

327 tests are large in all areas except medical interviewing (medium effect size) and

328 physical interviewing (small effect size) as per Cohen's criteria (1988) (Table 3).

329 Results for the Chi-Squared test indicate a significant association between improved

330 performance and HFS in all aspects except medical and physical interview skills $(\mathrm{p}=$

3310.31 and $\mathrm{p}=0.856$ respectively). 
333 Table 2: Demographic information

334

335 Table 3: Data for simulation and control groups

336

337 Student Reflections

338 Analysis of all 28 student reflections about their initial views of this learning method

339 resulted in three key themes; behaviour and attitudes, teaching ACBT to patients, and

340 feedback from 'patients'. Subthemes are shown in Figure 1, along with how they

341 interact.

342

343 Behaviours and attitudes

344 When working with peers students reported they would:

345 "become more distracted in class with our peers" $I_{3} / C_{9}$

346 And would:

"go off in tangents with peers/friends" $C_{4}$

352 when working with their peers as patients.

353 'More self-conscious with my peers" (B1)

354 This was in contrast to working with the SPs where students reported they felt the

355 need to behave more professionally and be more focused:

356 "more professional when looking around the class in the practical session" $I_{1}$

358 Teaching ACBT to Patients

359 Working with the SPs students' reported they were: 
362 They also reported that they had to focus more on their explanations of techniques

363 and the clarity of instructions:

364 "have to explain instructions and modify it" $I_{4}$

365

366 This may relate to the perception students had that their peers knew the techniques

367 and therefore did the correct technique without even needing instructions:

368 "peers know what they are asking therefore pre-emptively do it" I9

$371 \quad$ Feedback from 'Patients'

372 Students reported getting little feedback from their peers. This was in contrast to those

373 working with the SPs who reported that feedback from the SPs was much more

374 constructive:

375 "receive more accurate feedback on handling for example" $I_{6}$

\section{$\underline{\text { Discussion }}$}

380 The results of this exploratory study suggest practicing core respiratory skills on SPs

381 may have a positive impact on skill performance in physiotherapy students. A

382 statistically significant difference was found for counselling and communication

383 skills, clinical judgement, consideration of the patient and professionalism,

384 organisation and efficiency and clinical competency. Students also reported behaving 
more professionally, being better prepared and focused prior to the class and that the feedback received from SPs was more constructive.

Although a meaningful difference in scores for the MiniCEX has not been established in the literature, analysis indicates a large effect in favour of the HFS activity on key areas. This is further supported by Chi-Squared test results which indicate a statistically significant number of higher performing students in the HFS group. This suggests that practicing these core skills on SPs improves students' skill development and subsequent skill performance. However, this was only evidenced in areas directly 394 related to the class content.

Data provided by student reflections suggests the difference in performance may be due to: Improved knowledge prior to the practical class, increased focus during class,

398 having to modify instructions to ensure the SPs understood what was required and the 399 ability to effectively perform the required tasks in a safe, timely and efficient manner. 400 Increased focus also alludes to increased alertness which Sabus and Macauley argue 401 improves learning. ${ }^{7}$ Furthermore, students' reported receiving more detailed and 402 specific feedback from the SPs, which would enable them to modify and enhance 403 their technique, enabling reframing of knowledge and experience, promoting deeper 404 learning.

406 What was not measured was whether the quantity of practice that students' undertook 407 differed between the control and intervention groups. In addition to reporting 408 improved quality of practice with the SPs, there may have been more deliberate 409 practice which has been reported to improve skill development. ${ }^{33}$ Certainly comments 
410 relating to increased focus and fewer distractions with the SPs may infer improved

411 quality, if not quantity of practice. Transfer of learning to practice and retention of

412 learning were also not measured.

415 These findings are in direct contrast to the only other study found investigating HFS 416 for skill development in physiotherapy students. ${ }^{22}$ They found that students who had

417 practiced on peers had fewer safety fails and fails overall compared to those who

418 practiced on SPs. However, a fundamental difference between the studies may be in

419 the use of HFS. Students at the study facility have opportunities to practice

420 undertaking patient assessments on SPs during year one of the course. Consequently

421 they know what to expect and may have achieved sufficient stimulation and arousal

422 from the activity to keep them in the pleasant activation area identified in the

423 Circumplex Model of Affect. ${ }^{7}$ Students in the study of Phillips et $\mathrm{al}^{22}$ may have been

424 working in an unpleasant activation area due to stress from never having worked with

425 SPs before and this may have inhibited their learning. ${ }^{7}$ These conflicting findings

426 suggest that further research into the impact of SPs on skill development is warranted.

429 The two areas found not to improve from the SP interaction were medical and

430 physical interview skills. However, this result is unsurprising as these skills were not

431 a focus of the class that utilised the SPs, these skills having been taught previously

432 with peer practice. Results do indicate that medical interviewing skills was closer to

433 significance than physical interviewing skills. 
435 The focus for SP interactions was on teaching a patient a skill. Consequently, aspects

436 such as counselling and communication skills, professional skills and clinical

437 competence would be expected to improve. Teaching ACBT requires students to

438 explain and demonstrate the technique and the SPs are trained to give feedback on

439 communication skills and professionalism. Students' reported on the development of

440 communication skills due to the need to modify their explanations and communicate

441 more effectively with the SPs than with peers. They were also challenged by SPs

442 asking questions. The need to respond appropriately to SPs questions may have

443 influenced the students' clinical thinking. The results suggest there may be some

444 carry-over of generic skills such as communication and patient care, but the more

445 specific skills of structuring a patient interview which were taught with peer practice,

446 may have limited the degree of difference between groups in this area.

447

448 It is possible the difference between groups was not influenced by the SPs but by the

449 tutors facilitating the sessions. The LFS group was facilitated by a tutor with less

450 clinical and teaching experience than the HFS group. The HFS group may have

451 benefited from the greater level of clinical and teaching experience. Further studies

452 using a cross over design or using facilitators with similar experience levels may

453 therefore be beneficial.

454

455 Although the MiniCEX is validated for use with medical students it has not been

456 validated to be used in the assessment of practical skills performance with

457 physiotherapy students. It does not provide detail about specific aspects of each

458 technique and this may limit confidence in the results. Using a Likert scale also

459 introduces subjectivity to the evaluation of student performance, although using only 
one assessor helped control this variable. Unfortunately, there are no validated

461 outcome tools to measure skill performance in physiotherapy practice ${ }^{29}$ and therefore,

462 the MiniCEX was the most appropriate tool available. Another limitation highlighted

463 is the lack of generalisability due to the small sample from one university setting.

\section{Conclusion}

467 The findings of this study suggest that SP interactions may produce benefit to

468 physiotherapy students' skill performance. Further research with an adequate sample

469 size, using an outcome measure that has been validated to accurately measure specific

470 physiotherapy skill performance is required. If it is established that SP interactions

471 improve skill performance, it would then be beneficial to incorporate SP into

472 undergraduate physiotherapy educational practical classes and programs, and

473 investigate whether these enhanced skills are transferred to the clinical environment.

Ethical Approval

\section{7}

478 The study was approved by the School of Health Sciences Research Review group

479 (ref no:SHS/16/02); gatekeeper approval was gained from the course leader. 


\section{$\underline{\text { References }}$}

484

485

486

487

488

489

490

491

492

493

494

495

496

497

498

499

500

501

502

503

504

505

506

[1] World Congress on Physical Therapy. WCPT Guideline for Physical Therapist Professional Entry Level Education. London: World Congress on Physical Therapy; 2011. [Cited 2019 March 2] Available from: http://www.wcpt.org/guidelines/entry-level-education

[2] Howie P, Bagnall R. A critique of the deep and surface approaches to learning model. Teach High Educ. 2012;18:4,389-400. doi:

$10.1080 / 13562517.2012 .733689$

[3] Dolmans DHJM, Loyens SMM, Marcq H, Gijbels D. Deep and Surface Learning in Problem Based Learning: A Review of the Literature. Adv Health Sci Educ Theory Prac. 2016;21(5):1087-1112. doi: 10.1007/s10459-015-9645-6

[4] Levett-Jones T, Lathlean J. The Ascent to Competence Conceptual Framework: An Outcome of a Study of Belongingness. J Clin Nurs. 2009;18:2870-2879. doi: 10.1111/j.1365-2702.2008.02593.x

[5] Houghton CE, Casey D, Shaw D, Murphy K. Students' Experiences of Implementing Clinical Skills in the Real World of Practice. J Clin Nurs. 2012; 22:1961-9. doi: 10.1111/jocn.12014.

[6] Goulet C, Owen-Smith P. Cognitive-Affective Learning in Physical Therapy Education: From Implicit to Explicit. Journal of Physical Therapy Education. 2005;19(3):67-72.

[7] Sabus C, Macauley K. Simulation in Physical Therapy Education and Practice: Opportunities and Evidence-Based Instruction to Achieve Meaningful Learning Outcomes. Journal of Physical Therapy Education. 2016;30(1):3-13. 
[8] NHS Education for Scotland. NES Allied Health Professions Education Strategy. 2011. [Cited 2019 March 2] Available from: http://www.nes.scot.nhs.uk/media/5446/AHP-Strategy-The-Next-Chapter.pdf [9] Wright T, Moss P, Watson K, Rue S. Simulation in Physiotherapy Clinical

511 Training. National Simulated Learning Project. Final Report. Adelaide, Australia.

512 Health Workforce Australia. 2015. [Cited 2019 March 2] Available from:

513 http://lamp.physio.curtin.edu.au/simproj/HWA $\% 20$ Embedding $\% 20$ Simulation $\% 2$

$514 \quad$ 0in\%20Clinical\%20Physiotherapy\%20Final\%20Report.pdf

$515 \quad$ [10] World Health Organisation. Patient Safety Curriculum Guide.

516 Multiprofessional Edition. Geneva: World Health Organisation. 2011. [Cited

5172019 March 2] Available from:

518 http://apps.who.int/iris/bitstream/10665/44641/1/9789241501958 eng.pdf

519 [11] Korpi H, Peltokallio L, Piirainen, A. The Story Models of Physiotherapy

520 Students' Professional Development. Narrative Research. European Journal of

$521 \quad$ Physiotherapy. 2014;16:219-20. doi: org/10.3109/21679169.2014.934279

522 [12] Society for Simulation in Healthcare. Lopreiato JO (Ed.), Downing D,

523 Gammon W, Lioce L, Sittner B, Slot V, et al. (2016). Healthcare Simulation

524 Dictionary. [Cited 2018 June 29]. Available from:

$525 \quad$ http://www.ssih.org/dictionary.

526 [13] McGaghie WC, Issenberg SB, Petrusa ER, Scalese RJ, Jumah JAB, Ruland 527 JP. A Critical Review of Simulation-Based Medical Education Research: 2003528 2009. Med Educ. 2010;44(1):50-63. doi: 10.1111/j.1365-2923.2009.03547.x. 529 [14] Blackstock FC, Watson KM, Morris NR, et al. Simulation can Contribute a 530 Part of Cardiorespiratory Physiotherapy Clinical Education. Simul Healthcare. $531 \quad$ 2013;8:32-42. doi: 10.1097/SIH.0b013e318273101a 
533 Clinical Time? Two Parallel Randomised Controlled Trials. Med Educ.

534 2012;46:657-667. doi: j.1365-2923.2012.04295.x

535 [16] Silberman NJ, Litwin B, Panzarella KJ, Fernandez-Fernandez A. High

536 Fidelity Human Simulation Improves Physical Therapist Student Self-Efficacy for 537 Acute Care Clinical Practice. J Phys Ther Educ. 2015;29(4):14-24.

538 [17] Mandrusiak AM, Isles R, Chang AT, et al. Senior Physiotherapy Students as 539 Standardised Patients for Junior Students Enhances Self-Efficacy and Satisfaction 540 in Both Junior and Senior Students. BMC Med Educ. 2014;14:105.

$541 \quad$ https://doi.org/10.1186/1472-6920-14-105

542 [18] Hayward L, Blackmer B. A Model for Teaching and Assessing Core Values 543 Development in Doctor of Physical Therapy Students. J Phys Ther Educ. $544 \quad 2010 ; 24(3): 16-26$.

545 [19] Lewis M, Bell J, Asghar A. Use of Simulated Patients in Development of 546 Physiotherapy Student Interpersonal Skills. International Journal of Therapy and 547 Rehabilitation. 2008;15(5):221-7. doi: 10.12968/ijtr.2008.15.5.29234

548 [20] Boissonnault W, Morgan B, Buelow J. A Comparison of Two Strategies for 549 Teaching Medical Screening and Patient Referral in a Physical Therapist 550 Professional Degree Program. J Phys Ther Educ. 2006;20(1):28-36.

551 [21] Huhn, K., McGinnis, P.Q., Wainwright, S. \& Deutsch J.E. A Comparison of $552 \quad 2$ Case Delivery Methods: Virtual and Live. J Phys Ther Educ. 2013;27(3):4155348.

554 [22] Phillips AC, Macintosh SF, Bell A, Johnston KN. Developing Physiotherapy 555 Student Safety Skills in Readiness for Clinical Placement using Standardised 
Patients Compared with Peer-Role Play: A Pilot Non-Randomised Controlled Trial. BMC Med Educ. 2017; 17:133. doi: 10.1186/s12909-017-0973-5 [23] LeBlanc VR, Bould MD, McNaughton N, Brydges R, Piquette D, Sharma B. Simulation in Postgraduate Medical Education. Members of the FMEC PG consortium; 2011. [Cited 2019 March 2] Available from:

561 https://afmc.ca/pdf/fmec/18_LeBlanc_Simulation\%20and\%20Technology.pdf [24] Grove J, 7 key challenges for UK higher education. 2018 [cited 2018 Sept 26] Available from: https://www.timeshighereducation.com/features/7-key-

564 challenges-uk-higher-education [25] Orsmond GI, Cohn ES. The distinctive features of a feasibility study: Objectives and guiding questions. OTJR: 2015;35(5):169-77 [26] Liao KC, Pu SJ, Liu, MS, Yang, CW Kuo, HP. Development and Implementation of a Mini-Clinical Evaluation Exercise (mini-CEX) Program to Assess the Clinical Competencies of Internal Medicine Residents: From Faculty Development to Curriculum Evaluation. BMC Med Educ. 2013;13:31. doi: 10.1186/1472-6920-13-31. [27] Paravicini I, Peterson CK. Introduction, Development and Evaluation of the Mini Clinical Evaluation Exercise in Post-graduate Education of Chiropractors, $J o$ Chiropr Educ. 2015;29(1):22-28. doi: 10.7899/JCE-14-14. [28] Cresswell R. Research Design: Qualitative, Quantitative and Mixed Methods Approaches. $2^{\text {nd }}$ Ed. London: SAGE publishing; 2003. [29]Sattelmayer M, Hilfiker R, Baer G. A Systematic Review of Assessments for Procedural Skills in Physiotherapy Education. International Journal of Health Professions. 2017; 4(1): 53-65. Doi: 10.1515/ijhp-2017-0008. 
$581 \quad$ Evidence in Literature. Education in Medicine Journal. 2012;4(1)

582 doi:10.5959/eimj.v4il.8

583 [31] Pallant J. SPSS Survival Manual, chp 16 non-parametric statistics. $6^{\text {th }}$ Ed.

584 Maidenhead: McGraw-Hill.2010.

585 [32] Spencer 1, Ritchie J, O’Connor W. In: Ritchie J, Lewis J. Qualitative

586 Research Practice. A Guide for Social Scientists. London: Sage Publishing;

$587 \quad 2003: 199-21$.

588 [33] Welch TD, Carter M. Deliberate Practice and Skills Acquisition in Nursing

$589 \quad$ Practice. J Contin Educ Nurs. 2018;49(6):269-273.

590

591

592

593 
Table 1: Reflective questions asked

\begin{tabular}{|l|l|}
\hline LFS Group & HFS Group \\
\hline $\begin{array}{l}\text { What are your perceptions and views of the } \\
\text { interactions with your peers in practical and } \\
\text { simulation teaching? }\end{array}$ & $\begin{array}{l}\text { What are your perceptions and views of the } \\
\text { interactions with your peers in practical and } \\
\text { simulation teaching? }\end{array}$ \\
$\begin{array}{l}\text { What are your perceptions and views of the } \\
\text { interactions with the volunteers in practical } \\
\text { and simulation teaching? }\end{array}$ & $\begin{array}{l}\text { What are your perceptions and views of the } \\
\text { interactions with the volunteers in practical and } \\
\text { simulation teaching? }\end{array}$ \\
\hline
\end{tabular}

597

598

599 
Table 2: Student demographics

\begin{tabular}{|l|l|l|}
\hline & \multicolumn{1}{|c|}{ LFS } & HFS \\
\hline & $\mathrm{n}=14$ & $\mathrm{n}=14$ \\
\hline Male/Female (\%) & $21 / 79$ & $36 / 64$ \\
\hline Mean age $(\overline{\mathrm{x}})$ & 19.9 & 20.6 \\
Standard Deviation (SD) & 1.5 & 1.9 \\
\hline
\end{tabular}

601

602

603

604

605

606 
Table 3: Results MiniCEX

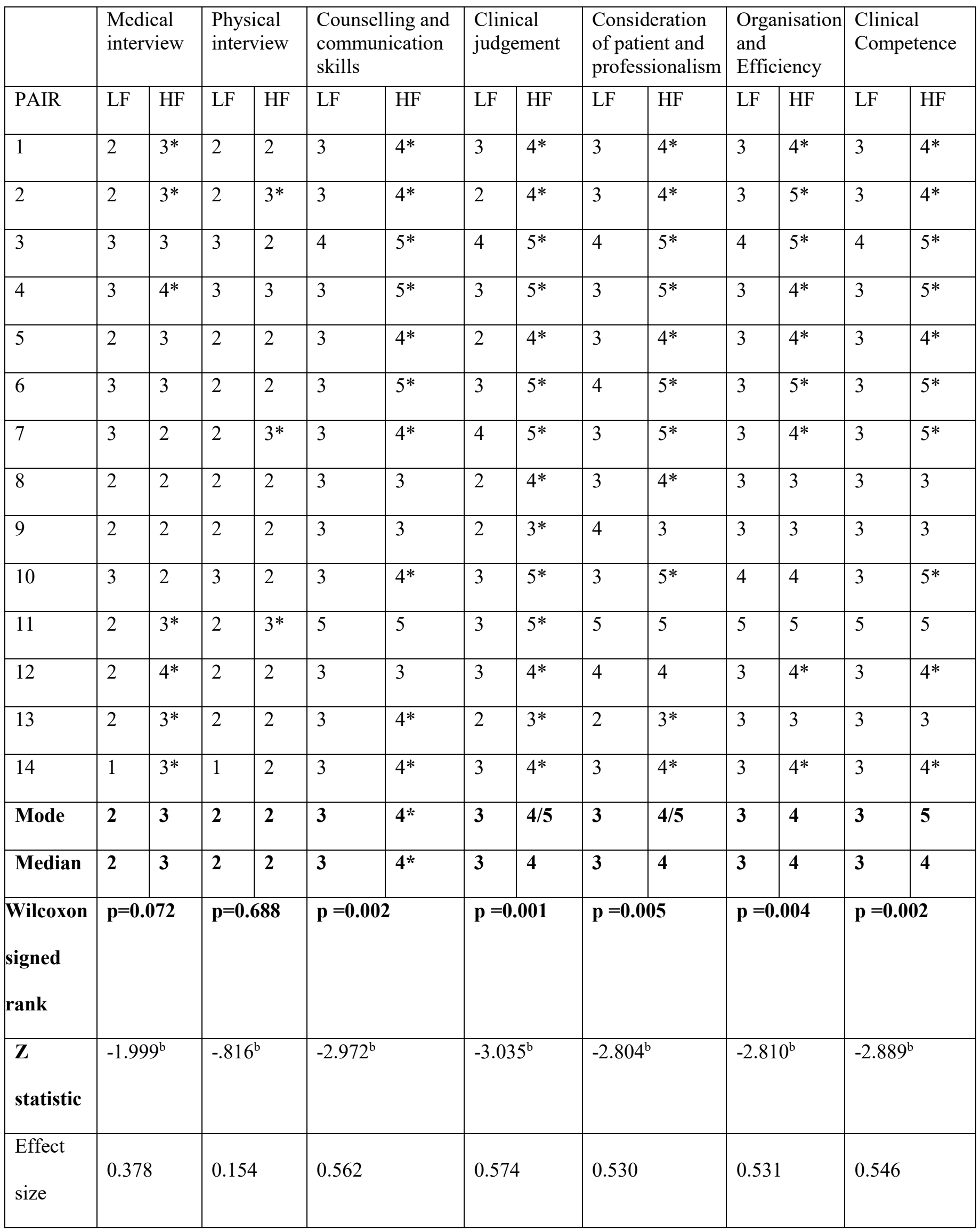




\begin{tabular}{|l|l|l|l|l|l|l|l|}
\hline $\begin{array}{l}\text { Cohen's } \\
\text { criterion } \\
(1988)\end{array}$ & Medium & Small & Large & Large & Large & Large & Large \\
\hline $\mathrm{Chi}^{2}$ & 0.31 & 0.856 & $<0.001$ & 0.002 & $<0.001$ & $<0.001$ & $<0.001$ \\
\hline
\end{tabular}

$\mathrm{LF}=$ low fidelity simulation group, $\mathrm{HF}=$ High fidelity simulation group,

$0=$ well below expectation $\quad 1=$ below expectation, $2=$ borderline, $3=$ meets

expectation, $4=$ above expectation, $5=$ well above expectation

$*=$ higher score in intervention group

$\mathrm{B}$ based on negative ranks 


\section{$\underline{\text { Figures }}$}

Fig 1: Themes and subthemes from student reflections
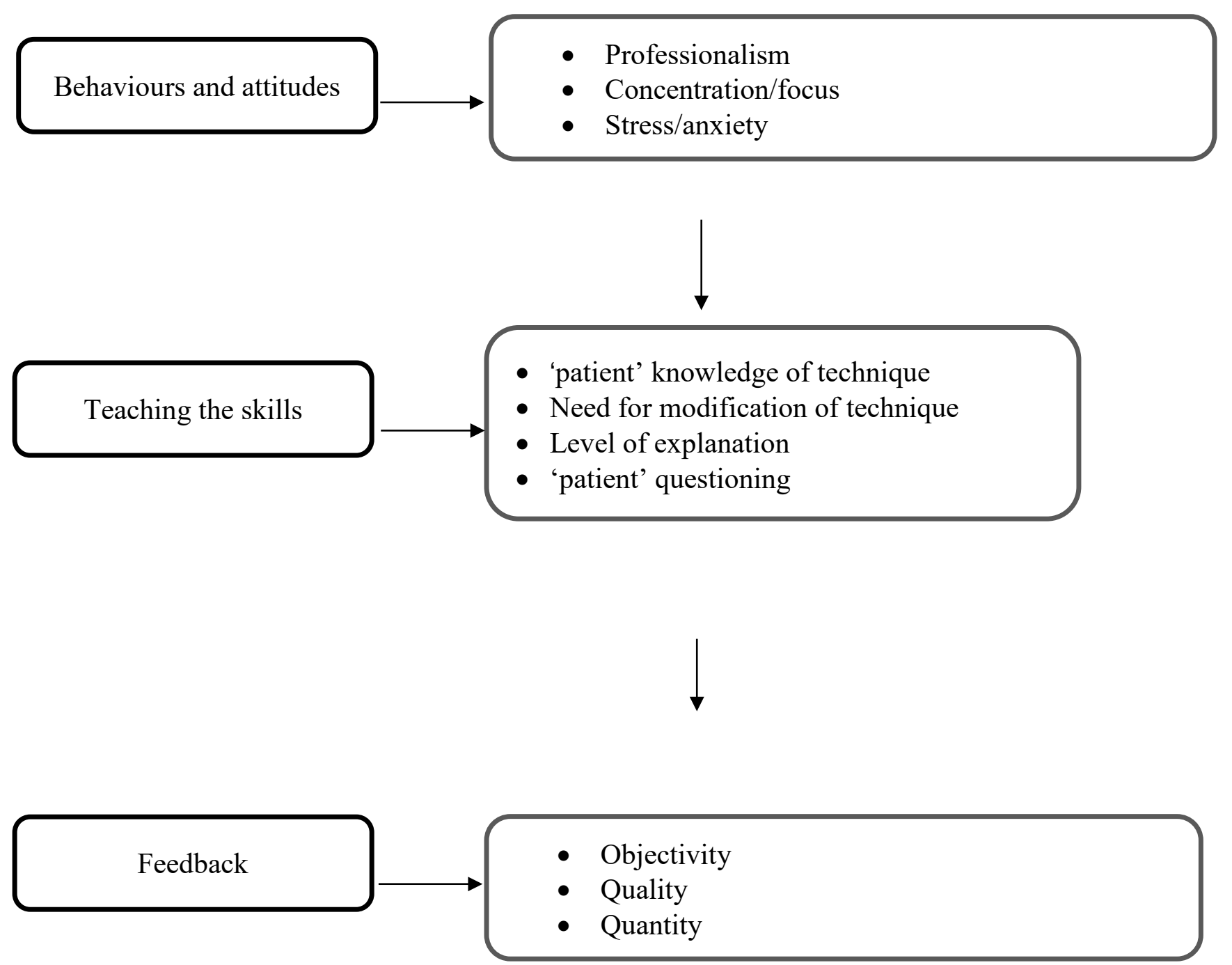


\section{APPENDIX: SESSION PLAN}

Aims of the session:

- To practise teaching the three components of ACBT (BC, TEE, and FET)

- To develop skills in modifying ACBT for patients with breathlessness, sputum retention, and loss of volume

Learning outcomes

By the end of the session, the student should be able to

- Effectively teach a patient to perform the components of ACBT.

- Modify their instructions and the performance of ACBT by a patient to ensure appropriate skills are performed.

- Use the components of ACBT in different positions to enhance treatment effect for patients.

Preparation:

Students directed to online video demonstrations of ACBT

Resources: (case studies, feedback sheets)

\begin{tabular}{lll}
\hline Programme/Course: & Unit: & Venue: \\
& Acute Care & \\
\hline Topic: & Level of study: & Date of session: \\
$\begin{array}{l}\text { Practical - ACBT for medical respiratory patients } \\
\text { Title of session: }\end{array}$ & 2 & Session no.: \\
Assessment practical & & Time of session: \\
Name of learning group: & & Duration of session: \\
& & $1 \mathrm{hr}, 50 \mathrm{~min}$
\end{tabular}

\begin{tabular}{ll}
\hline Time, min & Learning activities \\
\hline 10 & \\
& \\
5 & \\
& Students to practise teaching BC in groups of \\
& • three (patient, student, observer) or \\
& - two if SP group (student, observer) \\
& Observer and patient to provide feedback \\
& Swap patients and bed spaces so working with \\
& different people \\
& Students to practise teaching TEE, cycling back to BC in \\
& same groupings
\end{tabular}

Teaching activities

Learning outcomes for the session:

- Clarify feedback sheets, their role

- Role of patients - to be a patient, don't know the techniques

Review BC elements from video

Staff member to circulate around room providing feedback as appropriate to individual students and observer.

If appropriate, can draw group together if same common issue being identified:

- Focus on language used by students, hand positions, positioning of self, correction of patient, use of voice.

Staff member to circulate around room providing feedback as appropriate to individual students and observer.

If appropriate can draw group together if same common issue being identified. Emphasize the importance of proprioceptive feedback from hands:

- Focus on language used by students, hand positions, positioning of self, correction of patient, use of voice.

10 Students to practise teaching FET

$10 \quad$ Break

10 Review FET:

- May need to focus on keeping glottis open, ways to facilitate this.

Modify positioning for breathlessness, unilateral presentations of sputum retention, and loss of volume.

Modify technique for different problems:

- Incorporate holds and sniffs for loss of volume.

- Focus more on TEE and FET for sputum.

- Focus on BC for breathlessness. for breathlessness, sputum retention, and loss of volume Peers, patient, and tutor to provide feedback 
ACBT

Question

Yes

No

Comments

Did they introduce themselves with full name and "student physiotherapist"?

Did they check that they had the correct patient?

Did they ask what the patient would like to be called?

Did they explain what their role was and what they were going to do?

$\mathrm{BC}$ - did they include the following?

Tick if included

Comments

- Tidal breathing

- Should be relaxed.

- Aiming to help get more air to bottom of lungs.

- Is using diaphragm.

- Explain what diaphragm is.

- Position their hand just below xiphisternum.

- Encourage using a relaxed slow voice.

- Use analogies or modifications of explanation.

During $\mathrm{BC}$, circle any of the following that were used:

Push out Instruct when to breath in/out

General comments: Include whether therapist appropriately positioned her- or himself in relation to the patient, etc.

TEE

Tick if included

Comments

- Deep breath used

- Should think about getting air to the bottom at the sides.

- Fill the lungs from the bottom upward.

- Use a motivational voice to encourage deep breath.

- Appropriately position hands on lateral bases.

General comments:

FET

Tick if included

Comments

- Explains "It's like a cough but less effort."

- Explain about open glottis - no vocal sounds.

- Need to push air out short, sharp, and fast.

- Stop patient going past closing volume.

Other general comments to encompass non-verbal communication, use of voice, position and posture of physiotherapist:

$\mathrm{ACBT}=$ active cycle of breathing technique; $\mathrm{BC}=$ breathing control; TEE $=$ thoracic expansion exercises; $\mathrm{FET}=$ forced expiratory technique; $\mathrm{SP}=$ standardized patient. 